\title{
Solar Thermal Water Heater Operation under Thermosiphonic Mode of Flow
}

\author{
Ahmad Faizan Sherwani \\ Department of Mechanical Engineering, Jamia Millia Islamia
}

\begin{abstract}
In modern times there is a great need to find an alternate energy source to replace our dependence on fossil fuels which are depleting at a very fast rate. Solar energy is the best source of energy amongst all of the renewable sources of energy due to its large abundance. The present experimental study is focused on the study on thermosyphonic mode of operation in solar water heating system. The experimental setup consists of flat plate collectors, halogen system, cold and hot water storage tanks. Experimental study was conducted to investigate some specific parameters such as- Overall heat coefficient (UL.), Heat Removal Factor( FR), Efficency (n) In our experiments we intend to calculate some parameters as well as compare the results for thermosiphonic as well as with variation of radiation levels
\end{abstract}

Keywords: Thermosiphonic, Heat Removal Factor, Heat Coefficient factor

\section{Introduction}

India lying in the sub tropical region receives about 300 clear, sunny days in a year on only its land area, is about 5000 Petawatt-hours per year (PWh/yr) (i.e. 5,000 trillion $\mathrm{kWh} / \mathrm{yr}$ or about $600,000 \mathrm{GW})$. [1]The daily average solar energy incident over India varies from 4 to $7 \mathrm{kWh} / \mathrm{m}^{2}$ with about 1,500-2,000 sunshine hours per year (depending upon location), which is far more than current total energy consumption in India[2]

\section{Experimental Setup}

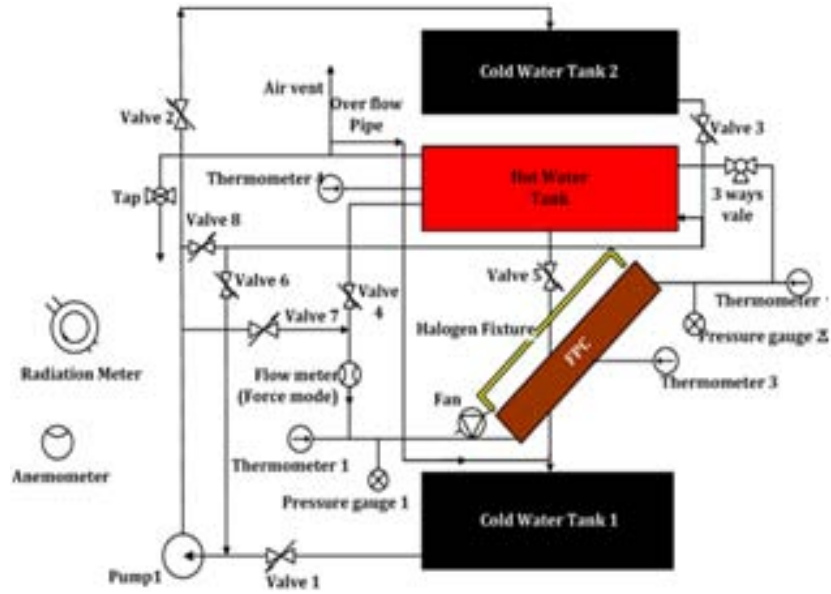

In this setup there are two cold water storage tank and one hot water storage tank. Water from cold tanks is fed to the hot water tank and the flat plate collector and the riser tubes.This collector receives the radiation from the halogen system resulting in heating of water which is already present in the collector tubes.Here the thermosyphonic[3] mode comes into play and natural flow of water starts.

In the hot water storage tank hot water starts filling due to the natural thermosiphonic mode and slowly the cycle continues till there is sufficient temperature difference between the hot water tank temperature and the flat plate collectors..[4] In order to compute the hot water flow rate through the risers,a three way valve pre-installed in the apparatus can be used.

In other experiment the radiation level is being varied from a minimum of 100 to maximum of $700 \mathrm{watt} / \mathrm{m}^{2}$ with the help of regulator present in the halogen system and the variation of efficiency of the [5] collector plate is being evaluated. The purpose of conducting these set of experiments is to make a model of the seasonal variation of the solar radiation while working in the natural conditions

\section{Thermosiphon Systems}

The thermosiphonic effect occurs because the density of water drops with the increase of the temperature. Therefore, by the action of solar radiation absorbed, the water in the collector is heated, becoming less dense, and rises through the collector into the top of the storage tank.

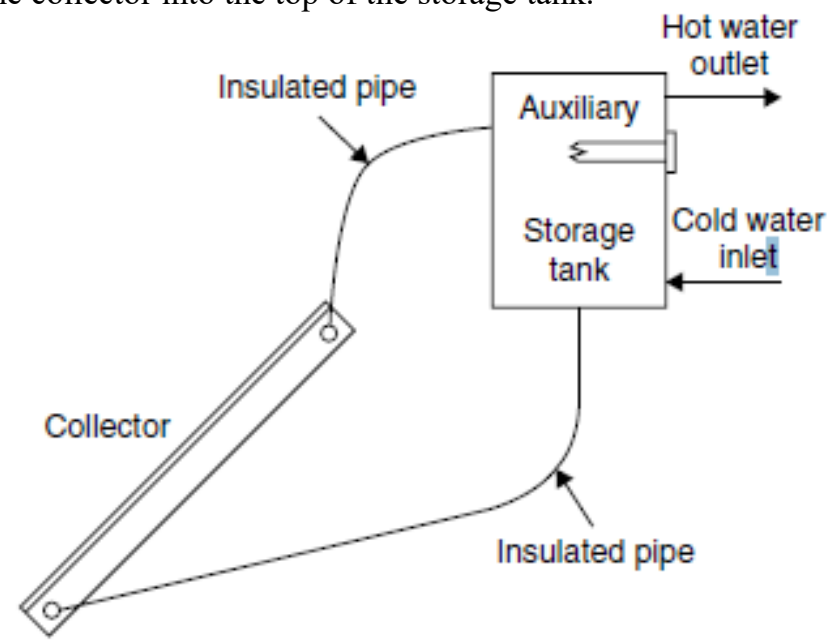

Figure: Schematic diagram of a thermosiphon solar water heater

The advantages of thermosiphon systems are that they do not rely on pumps and controllers, are more reliable, and have a longer life than forced circulation systems. Moreover, they do not require an electrical supply to operate and they naturally modulate the circulation flow rate in phase with the radiation levels 


\section{International Journal of Science and Research (IJSR) \\ ISSN (Online): 2319-7064}

Index Copernicus Value (2013): 6.14 | Impact Factor (2014): 5.611

\section{Components of Solar Water Heater}

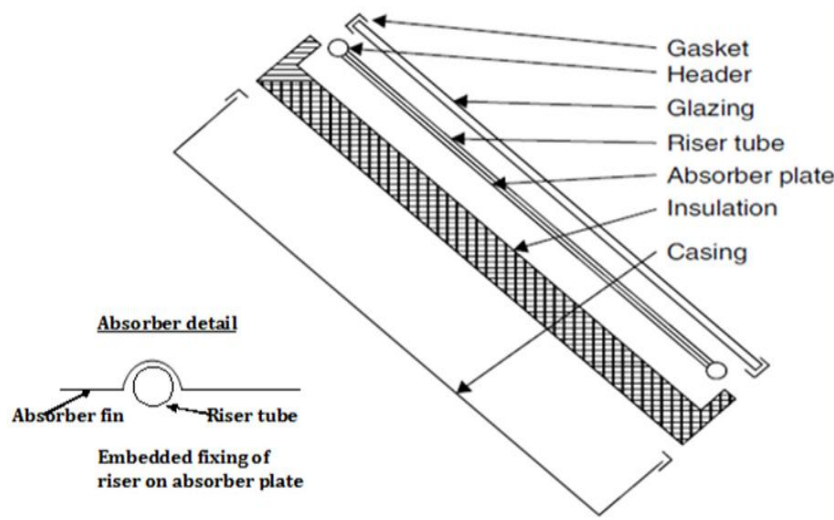

A typical flat-plate collector consists of an absorber plate in an insulated box together with transparent cover sheet(s).

- Absorber plate is a flat conducting plate to which the tubes, fins, or passages are attached. It may be a continuous or discrete plate. The plate is usually coated with a high absorptance and low emittance layer. Absorber material Copper Absorber plate thickness mm 0.12 Absorber plate dimension mm 115 Emissivity of surface $12 \%$ Absorption of surface $96 \%$

- Cover plate: One or more sheet of glass or other radiation-transmitting material forms the cover plate. The cover plate serves two purposes, minimization of convective heat loss and blocking of IR radiation.

- Heat removal passages: These are tubes, fins, or passages which conduct or direct the stream of water from the inlet to the outlet of the collector

- Headers or manifolds: These are the pipes to admit and discharge water that is meant to be heated.

- Overall data Overall collector dimension $\mathrm{mm}$ 915x810x95 Weight of the collector Kg 13 Aperture Area $\mathrm{m} 20.63$ [6]

\section{Important Parameters Of A Flat Plate Collector Based Solar Water Heating System}

Overall Heat loss coefficient $\left(\mathrm{U}_{\mathrm{L}}\right)$ :

All the heat that is generated by the collector does not resulted into useful energy. Some of the heat gets losses to the surroundings. The amount of heat losses depends upon the convective conductive and radiation heat loss coefficients.

Estimation of heat loss coefficient of the flat plate collector is important for its performance evaluation. A higher value of heat loss coefficient indicates the lower heat resistance and hence the lower efficiency.

Among all heat loss parameters the top loss contributes the most. The top heat loss coefficient is a function of various parameters which includes the temperature of the absorbing plate, ambient temperature, wind speed, emissivity of the absorbing and the cover glass plate, tilt angle etc.

$$
\mathrm{U}_{\mathrm{d}}=\mathrm{U}_{\mathrm{t}}+\mathrm{U}_{\mathrm{b}}+\mathrm{-1}
$$

Where $\left[, U_{b}\right.$ are the heat loss coefficients from top, bottom and edge of the plate.

$$
\begin{aligned}
& U_{t}=\left\{\frac{\frac{1}{N}}{\frac{C}{T_{D}}\left[\frac{T_{D}-T_{z}}{N+f}\right]^{0135}+\frac{1}{h_{\mathrm{z}}}}\right\} \\
& \text { A. }\left\{\frac{\sigma\left(T_{p}+T_{a}\right)\left(T_{D}^{2}+T_{a}^{2}\right)}{d\left(\varepsilon_{p}+0,05 N\left(1-\varepsilon_{p}\right)\right)^{-1}+\frac{2 N+f-s}{\sigma_{g}}}\right. \\
& \text { A. } U_{b}= \\
& \text { A. } U_{e}=U_{b} \text { ! }
\end{aligned}
$$

Nomenclature for the above mentioned parameters has been discussed later.

\section{Heat Removal Factor (FR)}

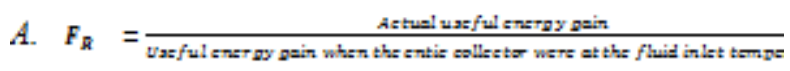

mathematically

$$
F_{R}=\frac{m C_{D}}{A_{E} U_{L}}\left[1-\exp \left(-\frac{U_{L} F_{L}}{m C_{F}}\right.\right.
$$

\section{Thermal Efficiency of the collector ( $n$ )}

It is the ratio of the Useful heat gain to the Total input energy Mathematically

$$
\eta=F_{R}\left[\left(\tau_{0} \alpha_{0}\right)-\frac{\mathbb{V}_{L}\left(T_{i}-:\right.}{u_{E}}\right.
$$

The formula given above is valid for normal incidence of radiation on the collector plate surface and also depicts the dependency on temperature difference, heat loss coefficient.

\section{Experimental Observations}

\section{Thermosiphonic mode with fixed parameters}

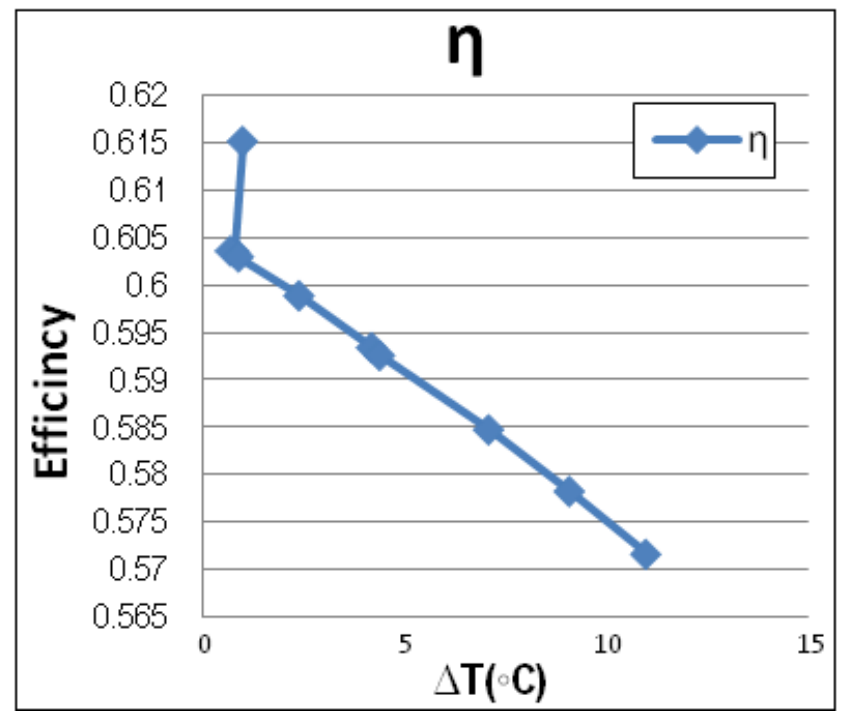

In the thermosiphonic mode of flow natural convection mode of heat transfer takes place. The thermosiphoning effect occurs because the density of water drops with the increase of the temperature. Therefore, by the action of solar radiation absorbed, the water in the collector is heated and thus expands, becoming less dense, and rises through the collector into the top of the storage tank. There it is replaced by the cooler water that has sunk to the bottom of the tank, from which it flows down the collector. Circulation is continuous as long as the sun is shining.[7]

\section{Volume 5 Issue 2, February 2016}




\section{International Journal of Science and Research (IJSR) \\ ISSN (Online): 2319-7064 \\ Index Copernicus Value (2013): 6.14 | Impact Factor (2014): 5.611}

Since the driving force is only a small density difference, larger than normal pipe sizes are used to minimize pipe friction. Connecting lines are well insulated to prevent heat loss and sloped to prevent formation of air pockets, which would stop circulation. The advantages of thermosiphon systems are that they do not rely on pumps and controllers, are more reliable, and have a longer life than forced circulation systems. Moreover, they do not require an electrical supply to operate and they naturally modulate the circulation flow rate in phase with the radiation levels.

The trend as shown in the above figure as observed by experimental calculations shows a decreasing nature with increase in temperature difference $\mathrm{b} / \mathrm{w}$ collector plate and fluid inlet temperature . Reason being that with the passage of time collector plate attains almost constant temperature (saturation level), inlet fluid temperature rises with passage of time due to constant heating. As we can see in the relation:-

$$
\eta=F_{R}\left[\tau_{0} \alpha_{0} \frac{\mathbb{U}_{1} \Delta \mathrm{T}}{\mathrm{I}_{\mathrm{t}}}\right]
$$

All the parameters remain constant except the change in temperature which is found to increase with time thus directly influencing efficiency and hence decreasing it. Also $\mathrm{U}_{1}$ value(heat loss coefficient ) also increases with passage of time as after saturation level is reached the plate refuses to accept more heat and the more is the temperature difference more will be the contribution of total heat input to the losses. Thus we obtain a decreasing nature for efficiency and the curves obtained are justified.

\section{Thermosiphonic mode with variation in Radiation levels}

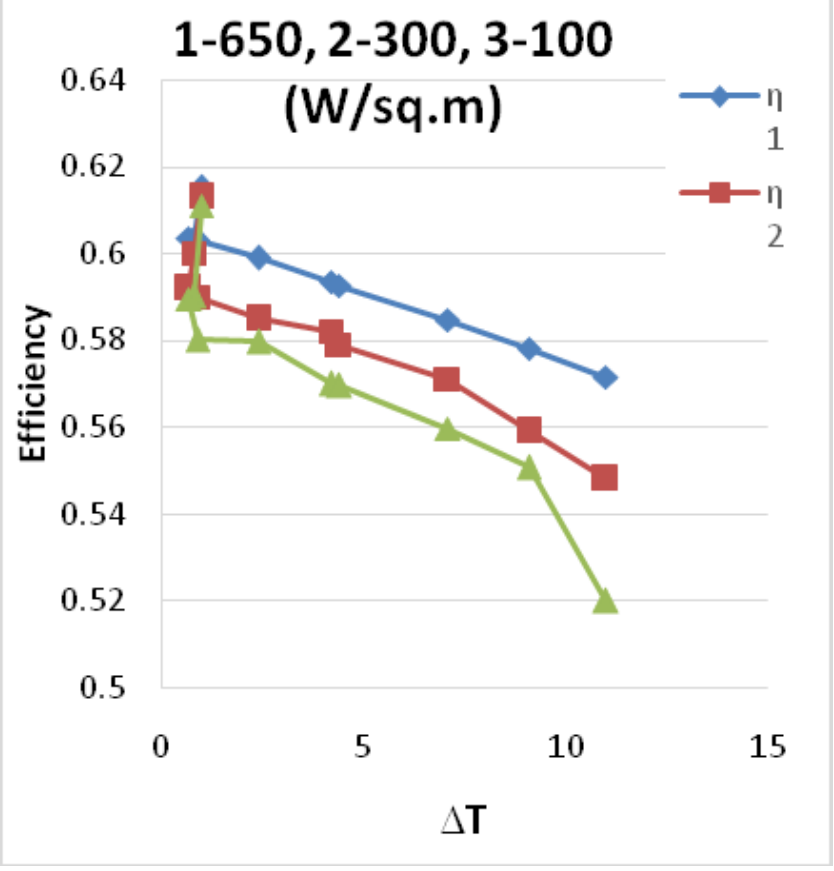

The general trend for the curves remains the same as the basic mode of operation remains the same i.e thermosiphonic mode of flow. However with the change in radiation levels a decreasing trend is observed as explained in the graphs plotted using experimental observations. As the level of radiations is reduced from 650 , then 300 and then to 100 ( all values in $\mathrm{W} / \mathrm{sq} \mathrm{m}$ ), we are reducing the incident solar energy on the collector plates to be available for water heating in the riser tubes. Thus in the nutshell we conclude that the efficiency levels obtained in the graphs are reducing with reduction in available solar radiation levels (which are varied using halogen regulator ). Thus the curves are justified in showing a decreasing trend with reduction in solar radiation level.

\section{Discussions}

The objective of the experiments performed were to study the effect of radiation intensity variation on the efficiency of the collector plate under the natural conditions, to do that we have created an artificial environment with artificial radiation source, the results obtained are in conformance with the results that were generated in the natural radiation conditions

With this experiment,it has been observed that the radiation levels, the insulation properties, the temperatures of the feed water and the environment are the most important chaercteristics that are going to determine the efficiency of a solar thermal system working under the thermosyphonic mode.It should be our primary objective to be able to maximize the incident radiation on the plate by using solar tracking devices and keep the plate perpendicular to the solar radiations. The various convective heat losses should be minimized by negating any air winds flowing across the plate surface.The thermal insulation of the plate material should be of the optimum quality to ensure high efficieny in the system.

One of the most important observation that has been made is that when the solar water heating system is allowed to run for a long duration of time, its efficiency keeps reducing.This observation can be attributed to the fact that as the temperature difference between the hot water in tank and collector plate reduces, the ability of water to extract heat from the flat plate collector also reduces.So,slowly the flow rate in the thermosiphonic mode gets reduced and similarly the rate of rise in temperature in the hot water tank also reduces.

The biggest advantage of flat-plate collectors are that they are inexpensive to manufacture, they collect both beam and diffuse radiation, and they are permanently fixed in position, so no tracking of the sun is required. The efficiency of the setup can be increased if Evacuated Tube Collectors \{ETC's\} are used ,the convectional heat losses are greatly reduced because of the vacuum envelope that is present around the riser tubes in ETC's. The Conventional simple flat-plate solar collectors that we are using works best in clear and sunny weather .

Around 60 deg. - 80 deg. $\mathrm{C}$ temperature can be attained depending on solar Radiation, weather conditions and solar collector system efficiency, stainless steel is used for small tanks whereas mild steel tanks with anti-corrosion coating inside are used for large tanks Solar water heaters (SWHs) of 100-300 litres capacity are suited for domestic application. A 100 litres capacity SWH can replace an electric geyser for residential use and saves 1500 units of electricity annually. The use of 1000 SWHs of 100 litres capacity each can 


\section{International Journal of Science and Research (IJSR) \\ ISSN (Online): 2319-7064}

Index Copernicus Value (2013): 6.14 | Impact Factor (2014): 5.611

contribute to a peak load shaving of $1 \mathrm{MW}$. Environment also gets benefit from these systems as a solar water heater of 100 liters capacity can prevent emission of 1.5 tonnes of carbon di oxide per year.

The other possible improvements that can be done are installation of freeze protection devices such as dump valve or heater at the bottom of the collector head . For locations that have a mild climate, the open loop thermosiphon solar water heater is the most widely used system. With freeze protection, thermosiphon systems can also be used in locations that experience minor freeze conditions. This can be provided by water dump valves, electric heating in the collector header, or tapered riser tubes to control ice growth in the riser so that a rigid and expanding ice plug is avoided (Xinian, et al., 1994).

Morrison and Braun (1985) studied the modeling and operation characteristics of thermosiphon solar water heaters with vertical or horizontal storage tanks. They found that the system performance is maximized when the daily collector volume flow is approximately equal to the daily load flow, and the system with horizontal tank did not perform as well as that with a vertical one, this model provides the basis of improvements in the collector.

In a nutshell the experiments performed help us in determining the seasonal variation of solar radiation incident on an average in India and also provide us with a means of utilizing solar energy for human benefit as well as reducing our dependency on fossil fuel powered electrical source.

\section{List of Symbols}

$\mathrm{A}_{\mathrm{c}}:$ Area of the collector $\left(\mathrm{m}_{2}\right)$

$\mathrm{Ae}_{\mathrm{e}}$ : Area of the edge $\left(\mathrm{m}_{2}\right)$

$\mathrm{C}_{\mathrm{p}}$ : Heat capacity of water $\left(\mathrm{kJ} /\left(\mathrm{kg}{ }^{\circ} \mathrm{C}\right)\right)$

$\mathrm{D}$ : Outer diameter of the risers $(\mathrm{mm})$

$\mathrm{H}_{\mathrm{fi}}$ : Heat transfer coefficient between the water and the riser

wall

$\mathrm{I}_{\mathrm{t}}$ : Radiation falling on the collectors per unit area $(\mathrm{W} / \mathrm{m} 2)$

$\mathrm{K}_{\mathrm{b}}, \mathrm{k}_{\mathrm{e}}$ :Conductivity of the back and edge insulation $(\mathrm{W} / \mathrm{mK})$

$\mathrm{k}$ : Conductivity of the fin $(\mathrm{W} / \mathrm{mK})$

$\mathrm{L}$ : Collector's length (mm)

$\mathrm{m}$ : Water mass flow rate $(\mathrm{kg} / \mathrm{sec})$

$\mathrm{N}$ : Number of glass cover

Ta: Ambient temperature $\left({ }^{\circ} \mathrm{C}\right)$

$\mathrm{T}_{\mathrm{P}}$ : Plate temperature $\left({ }^{\circ} \mathrm{C}\right)$

$\tau 0$ : Transmissivity of the glass cover

$\alpha 0$ : Absorptivity of the absorbing plate

ep: Emissivity of the absorbing plate

घg: Emissivity of the glass cover

\section{References}

[1] Muneer, T.; Asif, M.; Munawwar, S. (2005). "Sustainable production of solar electricity with particular reference to the Indian economy". Renewable and Sustainable Energy Reviews 9 (5): (publication archived in Science Direct, needs subscription or access via university)]

[2] India to unveil $20 \mathrm{GW}$ solar target under climate plan, Reuters, 28 July 2009

[3] Charters, W.W.S., de Forest, L., Dixon, C.W.S., Taylor, L.E., 1980. Design and performance of some solar booster heat pumps. In: ANZ Solar Energy Society Annual Conference, Melbourne, Australia

[4] Close, D.J., 1962. The performance of solar water heaters with natural circulation. Solar Energy 6 (1), 33-40.

[5] Furbo, S., Shah, L.J., 1997. Smart solar tanks-Heat storage of the future, ISES Solar World Congress. Taejon, South Korea.

[6] Morrison, G.L., 2001. Solar Water Heating. In: Gordon, J. (Ed.), Solar Energy: The State of the Art. James and James, London, pp. 223-289.

[7] Kalogirou, S., 1997. Design, construction, performance evaluation, and economic analysis of an integrated collector storage system. Renewable Energy 12 (2), 179 192

\section{Constants}

$\mathrm{Ac}=0.74115 \mathrm{~m} 2$

$\mathrm{Ae}=0.32775 \mathrm{~m} 2$

$\mathrm{K}_{\mathrm{b}}=0.04 \mathrm{~W} / \mathrm{m} \cdot \mathrm{k}$

$\mathrm{N}=1$ 